\title{
Fatigue Life Simulation and Analysis of Aluminum Alloy Sheet Self- piercing Riveting
}

Qingchun Zheng, Naixin Wang, Peihao Zhu*, Jingna Liu, Wenpeng Ma

Tianjin Key Laboratory for Advanced Mechatronic System Design and Intelligent Control, School of Mechanical Engineering, Tianjin University of Tecbnology, Tianjin 300384, Cbina

National Demonstration Center for Experimental Mechanical and Electric Engineering Education (Tianjin University of Technology)

zhengqingcbun@tjut.edu.cn,wangnaixin_up@163.com,_bupeihao_gp@163.com, liujingna2003@163.com, wenpengma@sina.com

\begin{abstract}
The fatigue life prediction model of self-piecing riveting components of aluminum alloy is established and the effects of roughness and residual stress on fatigue life are analyzed by the model. Finite element software ABAQUS and fatigue analysis software FE-SAFE are used to study the effects of roughness and residual stress on the fatigue life of self-piecing riveting components through finite element simulation and mathematical statistics multivariate orthogonal regression experiment. The quantitative relations between fatigue life and three variables (roughness, residual stress and maximum stress) are fitted, and the variation trend of fatigue life with roughness and residual stress is obtained. The order of influence of roughness, residual stress, maximum stress and two interactions on fatigue life is as follows: residual stress, interaction between roughness and residual stress, roughness. When the maximum stress is fixed, the fatigue life increases with the decrease of residual stress with a certain roughness, and the fatigue life decreases with the increase of roughness with a certain residual stress. The average error between the fatigue experiment results and the simulation results is $9.27 \%$, which proves that the simulation results are reliable.
\end{abstract}

KEYWORDS. Aluminum alloy; Self-piecing riveting; Surface roughness; Residual stress; Fatigue life; FE-SAFE.

\section{OPEN ACCESS}

Citation: Zheng, Q., Wang, N., Zhu, P., Liu J., Ma, W., Fatigue Life Simulation and Analysis of Aluminum Alloy Sheet Selfpiercing Riveting, Frattura ed Integrità Strutturale, 53 (2020) 141-151.

Received: 20.02 .2020

Accepted: 02.04 .2020

Published: 01.07.2020

Copyright: (C) 2020 This is an open access article under the terms of the CC-BY 4.0, which permits unrestricted use, distribution, and reproduction in any medium, provided the original author and source are credited.

\section{INTRODUCTION}

7 he lightweight development of G-Series high-speed railway has become an inevitable trend, among which aluminum alloy plays a more and more important part in the body materials of rail vehicles due to its low density, high specific strength and good wear resistance [1-3]. Self-piecing Riveting (SPR) is the main connection method 
of aluminum alloy thin plates at the present stage without punching being required. It adopts the principle of mechanical locking with a simple process, so that the thin plates can be effectively connected [4-6].

The fatigue life analysis of self-piercing riveting has been investigated by many scholars. Liu [7] investigated the mechanical properties and failure mechanisms of self-piercing riveted-bonded hybrid joints with carbon fiber reinforced polymers/aluminum alloy 5754. Zhang [8] studied the fatigue of self-piercing riveting joints connecting similar and dissimilar sheets of TA1 titanium alloy, Al5052 aluminum alloy and H62 copper alloy. Zhao [9] studied the influence of sheet thickness on the fatigue behavior and fretting of single-lap self-piercing riveted joints in aluminum alloy $5052 . \mathrm{Li}$ Huang [10] used experimental methods to study AA6111-T4 fatigue characteristics of aluminum alloy self-piercing riveting joints and fatigue prediction. Xing Baoying et al. [11,12] studied the influence of multiple rivet distributions on the mechanical properties and failure mechanism of joints, and thoroughly studied the macro and micro failure mechanisms of joints based on experiments. Deng Chengiiang et al. [13] studied the dynamic fatigue characteristics of self-piercing riveting allogeneic joints, and the results showed that the fatigue failure modes of aluminum alloy allogeneic joints were plate fracture. Xing[14]studied fatigue performance and failure mechanism of aluminum alloy self - piercing riveting head through fatigue testing, statistical methods, fracture analysis and elemental analysis of X-ray spectrometer. Sun et al. [15] comparatively analyzed the effects of substrate connection form, orientation, sheet thickness, harw22dness and adhesive on the fatigue performance of joints. The results showed that different board thicknesses and connection directions have significant effects on the fatigue strength of joints. Choi et al. [16] studied the effects of changes in riveting parameters on the mechanical properties of aluminum alloy self-piercing riveting joints and the mechanism of fatigue failure. It was found that when the fatigue cycle reached $75 \%$ of the total number, the fatigue strength of the joint gradually decreased, and at $90 \%$, the strength suddenly decreased. Di Franco et al .[17] studied the fatigue characteristics of self-piercing riveted joints of 2024 aluminum alloy and CFRP(Carbon Fiber reinforced plastics) plates through experiments and simulations, and found that composite joints have good fatigue properties. Ueda et al. [18] analyzed the fatigue characteristics of the joints of CFRP multilayer plates after optimized self-piercing riveting. The results showed that the rivets fail first at a load level lower than 80\%, and at a load level higher than 80\% CFRP multilayer materials failed first. Gay et al. [19] studied the fatigue performance of heterogeneous self-piercing riveted joints of aluminum alloy and glass fiber thermoplastic composites, and investigated the effects of rivet shape and high temperature environment on joint performance. Huang et al.[20] studied the fatigue performance of aluminum-steel heterogeneous metal self-piercing riveting joints with different thicknesses, and analyzed the fatigue failure mechanism of the upper and lower plate contact areas and the plate and rivet contact areas in detail.

This paper studies the fatigue simulation of self-piercing riveting joints based on the surface roughness of 5083 aluminum alloy sheet and residual stress of the components, and quantitatively determines the relationship between the fatigue life and three variables which are the surface roughness, residual stress and maximum stress of the components through regression orthogonal experiments. According to the quantitative relationship formula of the fatigue life, the change trend of the fatigue life with respect to the roughness and the residual stress is obtained, so as to provide relevant references for the practical application of the new technology on rail vehicles.

\section{FATIGUE SIMULATION BASED ON ABAQUS AND FE-SAFE}

$\mathrm{n}$ this paper, the fatigue analysis of self-piercing riveting joints is carried out by nominal stress method. The nominal stress method is based on the S-N curve of materials, taking into account the stress concentration factor and nominal stress at the dangerous position of structural fatigue, and adopts Miner linear fatigue cumulative damage theory to calculate the fatigue life. The analysis process is shown in Fig. 1.

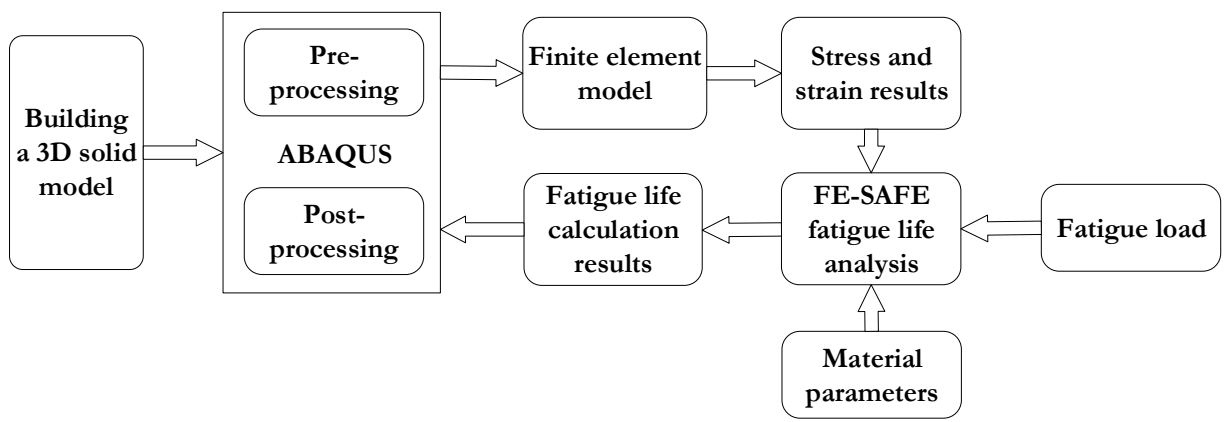

Figure 1: Flow chart of fatigue simulation analysis. 
S-N curve correction

The fatigue life of mechanical structural parts calculated from the material fatigue characteristic curve tends to be ideal, while factors such as stress concentration, shape size and surface processing technology of mechanical structural parts in actual engineering have a greater impact on fatigue strength. Therefore, when predicting the fatigue life of structural parts, the material fatigue characteristic curve is corrected and converted into the fatigue characteristic curve of the corresponding structural part to obtain a more accurate analysis result. Using the correction method proposed by Zhao Shaobian [21], in the number of cycles $N \leq 10^{4}$, the above-mentioned fatigue influencing factors have a small effect on the material, which can be ignored. When the number of cycles $N \geq 10^{4}$, the material fatigue strength will be reduced by a factor of $K_{\sigma}$, calculation method such as (1)

$$
K_{\sigma}=\frac{K_{\mathrm{t}}+\frac{1}{\beta}-1}{\varepsilon}
$$

where $K_{t}$ is the theoretical stress concentration factor; $\beta$ is the surface quality factor; and $\varepsilon$ is the dimensional coefficient of the structural part.

Query the appendix of "Anti-Fatigue Design-Methods and Data"[21], the stress concentration factor of self-piercing riveted members is $K_{t}=2$; according to the cold-working of self-piercing riveted members, the surface roughness is 2 $\mu m$, and combined with the "Anti-Fatigue Design-Methods and Data", the value is $\beta=0.5$; $\varepsilon$ can be calculated by the following empirical formula:

$$
\varepsilon=\left(\frac{v}{v_{0}}\right)^{-0.034}
$$

where $v_{0}$ is the material volume of parts subjected to the maximum stress of more than $95 \%$; $v$ is the material volume of standard samples similar to the geometry of parts subjected to the maximum stress of more than $95 \%$.

When the number of cycles is $10^{7}$, the fatigue limit correction formula is

$$
\sigma_{-1}^{\prime}=\frac{\sigma_{-1}}{K_{\sigma}}
$$

where $\sigma_{-1}$ is the initial fatigue correction factor; $K_{\sigma}$ is the factor of fatigue strength reduction.

After the above correction method, the S-N curve of the standard sample material is corrected to obtain the S-N curve of the actual structural part, and the slope of the high-cycle fatigue interval line segment of the fatigue characteristic curve of the self-piercing riveted member is obtained through calculation:

$$
k_{1}=\frac{\lg S_{r e q}-\lg \sigma_{-1}^{\prime}}{\lg 10^{4}-\lg 10^{7}}
$$

The modified Miner Rule is used to modify the small load under the fatigue limit to obtain the S-N curve of the selfpiercing riveted member, as is shown in Fig. 2.

\section{Static analysis}

In order to more accurately simulate the stress and fatigue life of the self-piercing riveted piece, the fatigue simulation is performed using the size of the fatigue experimental sample, as is shown in Fig. 3, and based on the mapping results, Solidworks is used to establish a self-piercing riveting joint model, as is shown in Fig. 4.

In the actual fatigue experiment, the self-piercing riveting joint is fixed at both ends and pulled at the same time. Therefore, in the static analysis, the left end of the component joint is fixed and the right end is subjected to a constant load with a load of $1 \mathrm{kN}$. In order to improve the accuracy of the calculation, eight-node hexahedral solid elements are 
used in the model, which is divided by the method of sweeping the mesh that is refined at the riveting point. The total number of elements is 124993 and the total number of nodes is 153607.

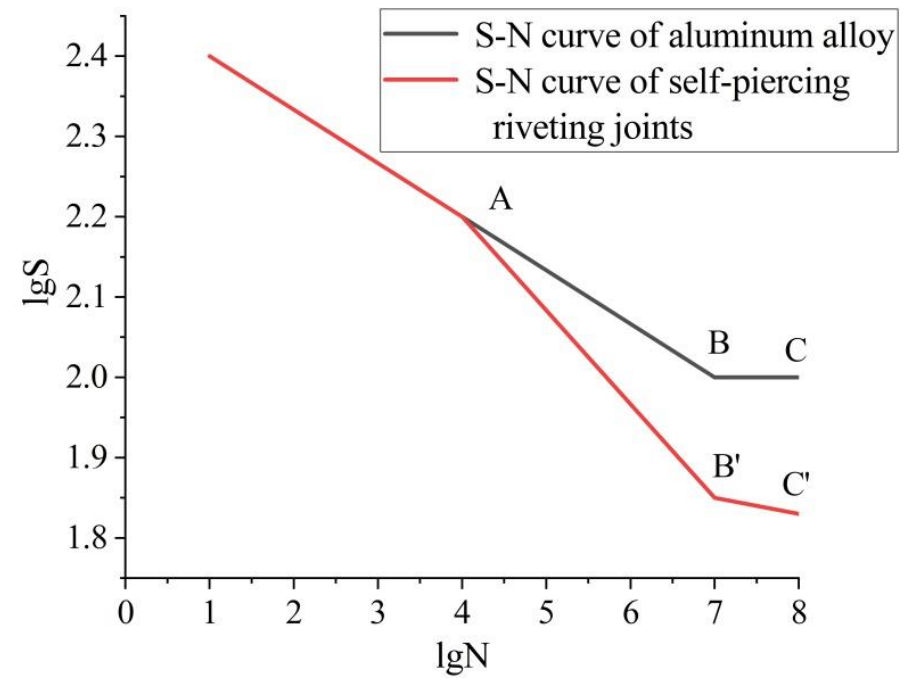

Figure 2: S-N Curve of the joints.

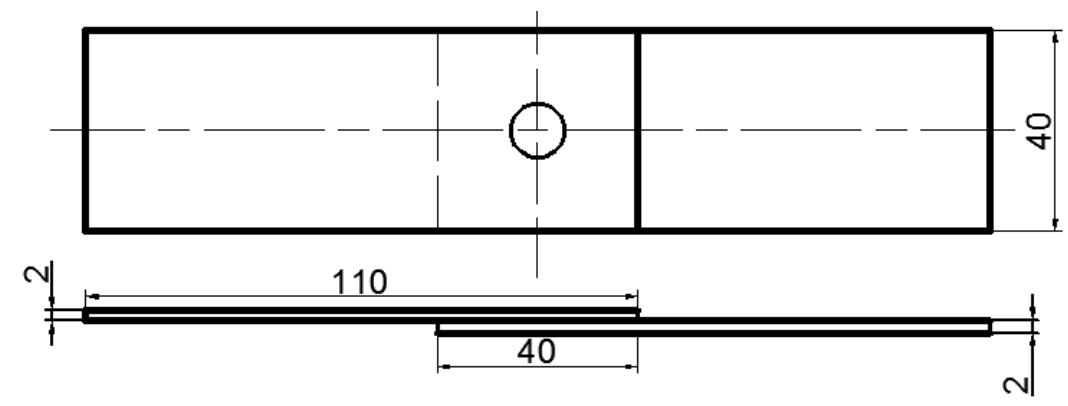

Figure 3: Size of the self-piercing riveting specimen.

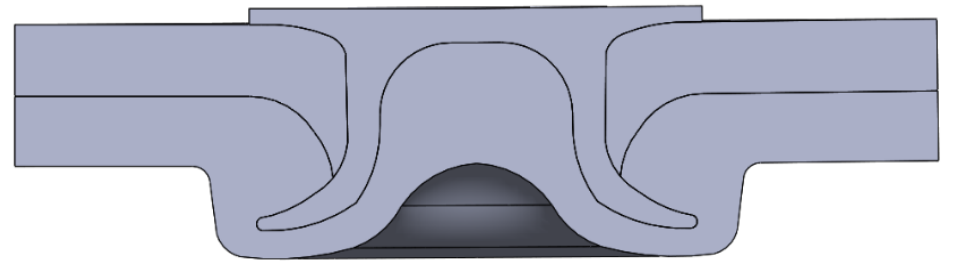

Figure 4: Self-piercing riveting 3D model.

\begin{tabular}{ccccc}
\hline & Materials & Density $\left(\mathrm{kg} / \mathrm{m}^{3}\right)$ & $\begin{array}{c}\text { Elastic Modulus } \\
(\mathrm{MPa})\end{array}$ & Poisson's ratio \\
Sheet & $\begin{array}{c}5083 \\
\text { Aluminum }\end{array}$ & $2.71 \times 10^{-15}$ & $7 \times 10^{4}$ & 0.33 \\
Rivet & $36 \mathrm{MnB} 4$ & $7.87 \times 10^{-15}$ & $2.09 \times 10^{5}$ & 0.28 \\
\hline
\end{tabular}

Table 1: Material parameters.

Fig. 6 shows the stress cloud diagram of the static simulation Von Mises. According to the stress cloud diagram, the most critical part of the riveting joint is the contact between the rivet leg and the plate, and the maximum stress is $283 \mathrm{MPa}$. 


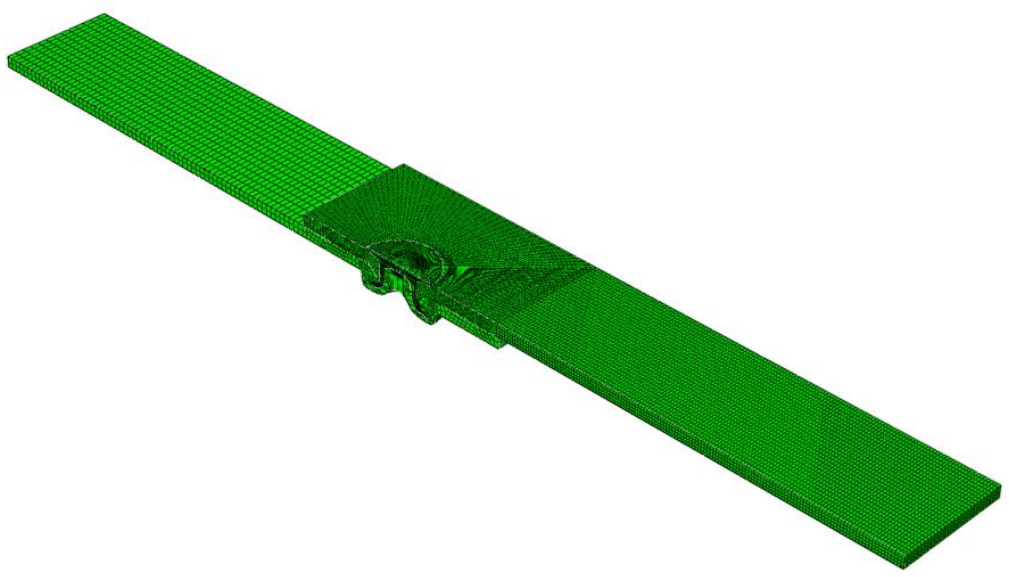

Figure 5: Mesh of the self-piercing riveting specimen.
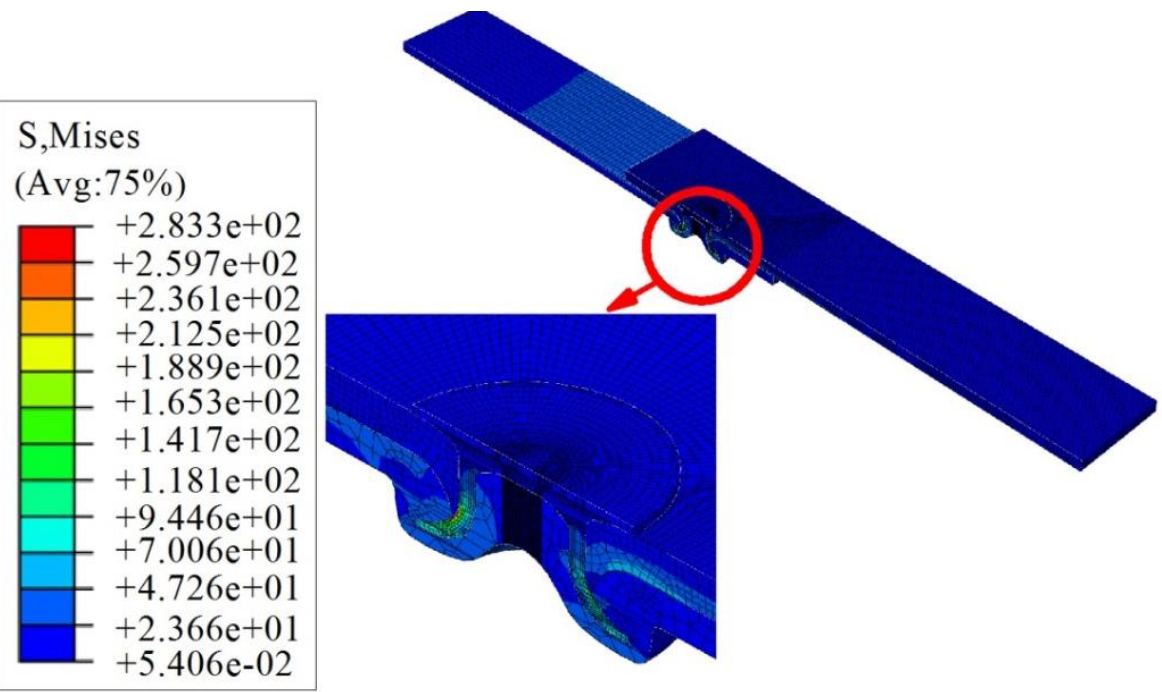

Figure 6: Stress cloud of the self-piercing riveting specimen.
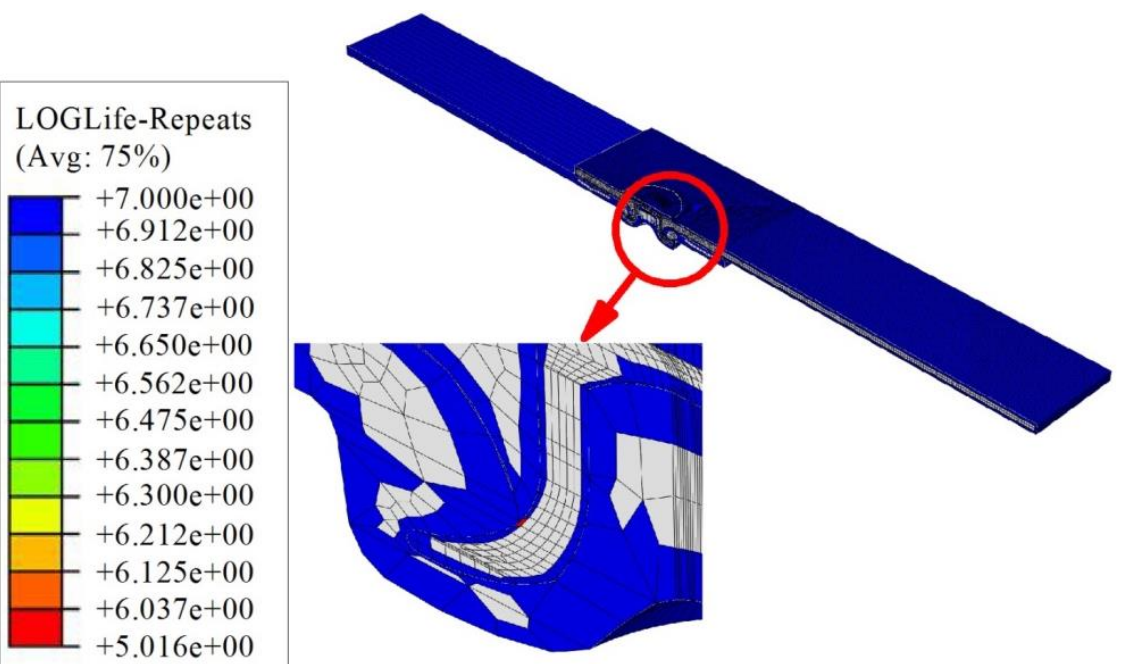

Figure 7: Fatigue simulation cloud of self-piercing riveting specimen 


\section{Fatigue life simulation analysis}

Based on the finite element analysis, FE-SAFE is used for full life (S-N) analysis. The software requires as inputs, the 5083 aluminum alloy's tensile strength (UTS) and the elastic modulus in the "Material", the S-N curve, shown in Fig. 2 and the load history. The stress of fatigue simulation is the product of the stress of finite element analysis and the transient value of load history. The applied stress is the maximum load stress in the static analysis process, therefore, the load time history should be the unit load in the fatigue simulation. The load type is a sine wave, and the stress ratio is $\mathrm{R}=0.1, \mathrm{f}=20 \mathrm{~Hz}$. Finally, define the surface state of the component, and input the surface roughness and residual stress in the Surface and Residual windows, respectively.

The fatigue simulation results are shown in Fig. 7 characterized by a maximum stress of $283 \mathrm{MPa}$, a roughness of $1 \mu \mathrm{m}$ and a residual stress of $-300 \mathrm{MPa}$. It can be seen from the figure that the position with the minimum fatigue life is the lower part of the rivet leg that is in contact with the upper plate. The crack initiates in this area, then under the action of the alternating load, it continues to expand and finally breaks, causing the riveting failure. And the minimum fatigue life is $10^{5.016}=103753$ times.

\section{FATIGUE SIMULATION EXPERIMENT BASED ON MULTIPLE ORTHOGONAL REGRESSION ANALYSIS METHOD}

$\mathrm{R}$ esidual stress in the riveting process and surface roughness of the thin plate are two important factors that affect the fatigue life. On the one hand, the residual stress can cause plastic deformation and disrupt the stress balance of the riveted components. On the other hand, due to the micro unevenness on rough surface, it is easy to form stress concentration, the formation of which accelerates the generation of cracks. These two factors generally affect the fatigue life in a comprehensive way, therefore, it is difficult to quantitatively evaluate the influence of a single factor.

Based on orthogonal experiments and regression analysis methods, this paper designs a multiple regression orthogonal experiment to fit a multiple linear regression equation to determine the fatigue life $N_{\text {cycles }}$ and residual stress $x_{1}$, roughness $\mathrm{x}_{2}$, maximum stress $\mathrm{x}_{3}$ and interaction $\mathrm{x}_{1} \cdot \mathrm{x}_{2}, \mathrm{x}_{1} \cdot \mathrm{x}_{3}, \mathrm{x}_{2} \cdot \mathrm{x}_{3}$ functional relationship. During the riveting process, the surface roughness value $R_{Z}$ of the aluminum plate ranges from 1 to $5 \mu \mathrm{m}$, the residual stress value ranges from -300 to 100 , and the maximum stress range is 100 to $500 \mathrm{MPa}$.

To facilitate the design of subsequent orthogonal experiments, the levels of each factor $\left(\mathrm{x}_{1}, \mathrm{x}_{2}, \mathrm{x}_{3}\right)$ is respectively encoded into $z_{1}, z_{2}$ and $z_{3}$ through formula (5). And the encoding results are shown in Tab. 2.

$$
z_{j}=\left(x_{j}-x_{j 0}\right) / \Delta_{j}
$$

\begin{tabular}{cccc}
\hline Factor $\left(\mathrm{x}_{\mathrm{j}}\right)$ & $\mathrm{R}_{\mathrm{Z}} / \mu m$ & Residual stress/ MPa & Maximum stress/ MPa \\
Top level $\left(\mathrm{x}_{\mathrm{j} 1}\right)$ & 5 & 100 & 500 \\
Bottom level & 1 & -300 & 100 \\
$\quad\left(\mathrm{x}_{\mathrm{j}(-1)}\right)$ & 3 & -100 & 300 \\
Zero level $\left(\mathrm{x}_{0}\right)$ & 2 & 200 & 200 \\
Change block $(\mathrm{j})$ & & & \\
\hline
\end{tabular}

Table 2: The factor code table.

Based on the above experimental factors, an orthogonal table is selected, and after the code conversion, the regression orthogonal table shown in Tab. 3 is obtained. Columns 1,3 , and $5\left(z_{1}, z_{2}\right.$ and $\left.z_{3}\right)$ are codes corresponding to residual stress, roughness, and maximum stress. Columns 2,4 , and $6\left(z_{1} z_{2}, z_{1} z_{3}\right.$ and $\left.z_{2} z_{3}\right)$, respectively, are interactions of two factors. The total number of tests is $n=8$. Fe-safe is used to calculate the fatigue life under different conditions. The test results are shown in Tab. 3. Origin is used for regression analysis and variance analysis. See Tab. 4 for the calculation process.

The results of the orthogonal regression are shown in Tab. 4 and Tab.5. From Tab.5, it can be seen that when the two factors interact, the interaction between roughness and residual stress is greater than the interaction between the other two 
factors because of 100165.1 $\left(z_{1} z_{2}\right)>7605.13\left(z_{1} z_{3}\right)>5961.13\left(z_{2} z_{3}\right)$; when the single factor interacts, the effects of maximum stress, roughness, and residual stress increase sequentially because of $12482.1\left(z_{3}\right)>112798\left(z_{2}\right)>91024\left(z_{1}\right)$; when comprehensively considered, residual stress $>$ roughness and residual stress interaction $>$ roughness.

\begin{tabular}{ccccccccccc}
\hline $\begin{array}{c}\text { Experiment } \\
\text { number }\end{array}$ & $z_{1}$ & $z_{1} z_{2}$ & $z_{2}$ & $z_{1} z_{3}$ & $z_{3}$ & $z_{2} z_{3}$ & $\begin{array}{c}\text { Roughness } \\
/ \mu m\end{array}$ & $\begin{array}{c}\text { Residual } \\
\text { Stress/ MPa }\end{array}$ & $\begin{array}{c}\text { Maximum } \\
\text { stress } / \\
M P a\end{array}$ & $\begin{array}{c}\text { Fatigue } \\
\text { life } \\
/ \text { time }\end{array}$ \\
1 & 1 & 1 & 1 & 1 & 1 & 1 & 5 & 100 & 500 & 459 \\
2 & 1 & 1 & 1 & -1 & -1 & -1 & 5 & 100 & 100 & 19929 \\
3 & 1 & -1 & -1 & 1 & 1 & -1 & 5 & -300 & 500 & 5020 \\
4 & -1 & 1 & -1 & -1 & 1 & -1 & 1 & -300 & 500 & 123392 \\
5 & -1 & -1 & 1 & -1 & 1 & 1 & 1 & 100 & 500 & 606 \\
6 & -1 & 1 & -1 & 1 & -1 & 1 & 1 & -300 & 100 & 436286 \\
7 & 1 & -1 & -1 & -1 & -1 & 1 & 5 & -300 & 100 & 65899 \\
8 & -1 & -1 & 1 & 1 & -1 & -1 & 1 & 100 & 100 & 7220 \\
\hline
\end{tabular}

Table 3: Ternary regression orthogonal experimental design and analysis of simulation results.

\begin{tabular}{cc}
\hline Parameter & Result \\
Multiple R & 0.999703 \\
R square & 0.999406 \\
Adjusted TR square & 0.995839 \\
Standard error & 12419.98 \\
Observation value & 8 \\
\hline
\end{tabular}

Table 4: Ternary orthogonal regression analysis data sheet.

\begin{tabular}{lll}
\hline & Coefficients & P value \\
Intercept & 119851.4 & 0.023314 \\
$z_{1}$ & -91024.6 & 0.028792 \\
$z_{1} z_{2}$ & 100165.1 & 0.027891 \\
$z_{2}$ & -112798 & 0.024771 \\
$z_{1} z_{3}$ & -7605.13 & 0.333352 \\
$z_{3}$ & -12482.1 & 0.21535 \\
$z_{2} z_{3}$ & 5961.13 & 0.404182 \\
\hline
\end{tabular}

Table 5: Correlation coefficient and P value. 
According to the results, an orthogonal regression equation is obtained, as is shown in formula (6). When the codes $z_{1}, z_{2}$, $z_{3}$ are converted into $x_{1}, x_{2}, x_{3}$ respectively, the formula (6) is transformed into formula (7), so that the quantitative relationship between fatigue life and residual stress, roughness, maximum stress is obtained. In the subsequent related research, the fatigue life of the rivet structure can be directly estimated by using matlab based on the quantitative relationship, saving a certain amount of experimental time and experimental cost.

\begin{tabular}{cccccc}
\hline & Degree Freedom & Stdev Square & Mean Square & F statistics & Saliency \\
Regression analysis & 6 & $2.5 \mathrm{E}+11$ & $4.32 \mathrm{E}+10$ & 280.22 & 0.0456 \\
Residual & 1 & $1.5 \mathrm{E}+08$ & $1.54 \mathrm{E}+08$ & \\
Total & 7 & $2.6 \mathrm{E}+11$ & & \\
\hline
\end{tabular}

Table 6: Significance analysis.

$$
\begin{aligned}
& \mathrm{N}_{\text {cycles }}=119851.4-97024.6 \cdot z_{1}+106151 \cdot z_{1} \cdot z_{2}-118783.7 \cdot z_{2} \\
& -12793.6 \cdot z_{1} \cdot z_{3}-6496.3 \cdot z_{3}+11149.6 \cdot z_{2} \cdot z_{3}
\end{aligned}
$$

where $N_{\text {cycles }}$ is the fatigue life; $z_{1}$ is level code of the residual stress; $z_{2}$ is the level code of the roughness; $z_{3}$ is level code of the maximum stress.

$$
\begin{aligned}
& \mathrm{N}_{\text {cycles }}=119851.4-97024.6 \cdot\left[\left(\mathrm{x}_{1}-3\right) / 2\right]+106151 \cdot\left[\left(\mathrm{x}_{1}-3\right) / 2\right] \cdot\left[\left(\mathrm{x}_{2}+100\right) / 200\right] \\
& -112798 \cdot\left(\left(\mathrm{x}_{2}+100\right) / 200\right)-7605.13 \cdot\left[\left(\mathrm{x}_{1}-3\right) / 2\right] \cdot\left[\left(\mathrm{x}_{3}-300\right) / 200\right] \\
& -12482.1 \cdot\left[\left(\mathrm{x}_{3}-300\right) / 200\right]+5961.13 \cdot\left[\left(\mathrm{x}_{2}+100\right) / 200\right] \cdot\left[\left(\mathrm{x}_{3}-300\right) / 200\right]
\end{aligned}
$$

where $\mathrm{N}_{\text {cycles }}$ is the fatigue life; $\mathrm{x}_{1}$ is the residual stress; $\mathrm{x}_{2}$ is the roughness; $\mathrm{x}_{3}$ is the maximum stress.

The maximum stress under working conditions is $450 \mathrm{MPa}$, and the change trend of fatigue life with respect to roughness and residual stress is shown in Fig. 8. When the roughness is constant, as the residual stress decreases, the fatigue life gradually increases. Under fatigue conditions, as the roughness increases, the fatigue life gradually decreases.

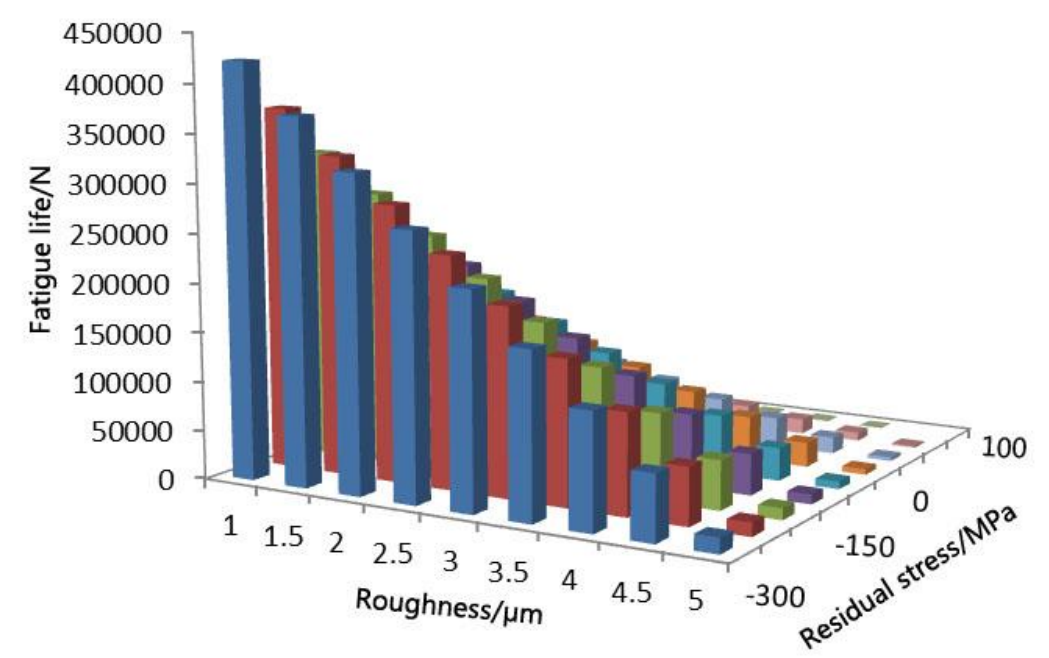

Figure 8: The relationship between fatigue life and roughness and residual stress under 450MPa. 


\section{FATIGUE EXPERIMENT}

A luminum plates with different roughness are selected and cut into specimens using electric spark cutting equipment, and riveted with different self-piercing riveting machines to make 5 different samples groups with different roughness and residual stress. And each group consists of three samples. Roughness tester and X-ray diffraction stress tester are used to test the sample parameters.

The MTS landmark100 electro-hydraulic servo material testing machine is selected. The specimen is clamped in the machine as is shown in Fig. 9. The maximum stress is $450 \mathrm{MPa}$, the stress ratio is $\mathrm{R}=0.1$ and the frequency is $\mathrm{f}=20 \mathrm{~Hz}$. The sinusoidal stress is used for the tensile-tensile fatigue test. The failed SPR joints for the fatigue tests are shown in Fig. 10.

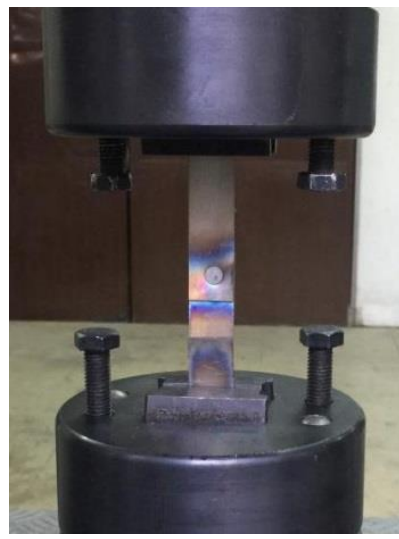

Figure 9: Clamping specimen.

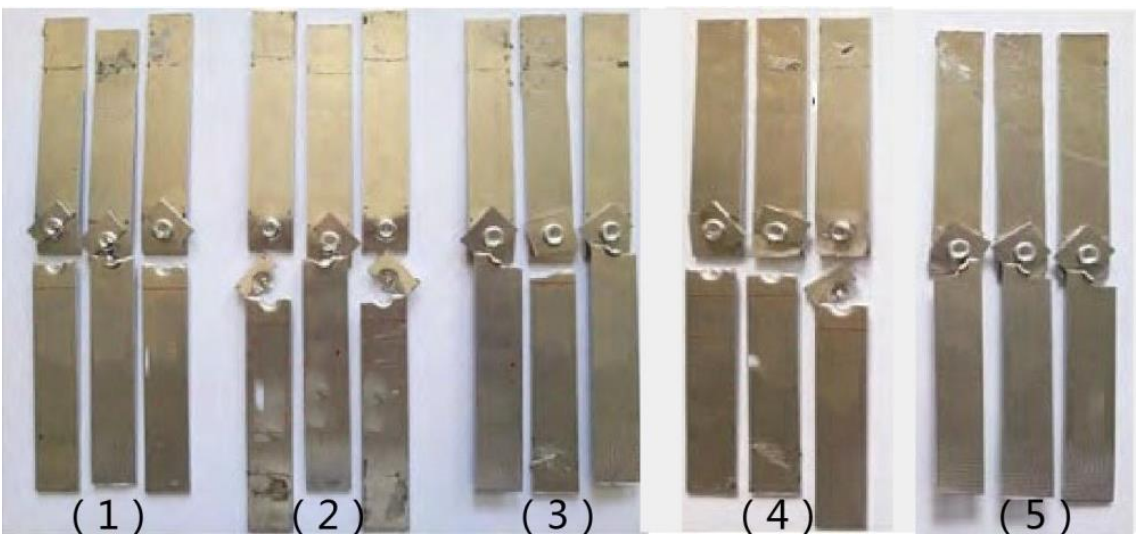

Figure 10: Different failed SPR joints for the fatigue tests.

The experimental results are shown in Tab. 7. Under the conditions of preset roughness and residual stress, the simulation and experiments are performed on the self-piercing riveting members of aluminum alloy thin plates. The fatigue results of the two are in the same order of magnitude, and the average error is $9.27 \%$.

\begin{tabular}{|c|c|c|c|c|c|}
\hline $\begin{array}{l}\text { Experiment } \\
\text { examples }\end{array}$ & $\begin{array}{l}\text { Roughness } \\
\mathrm{R}_{\mathrm{Z}}\end{array}$ & $\begin{array}{l}\text { Residual Stress } \\
/ \mathrm{MPa}\end{array}$ & $\begin{array}{l}\text { Simulation Results } \\
\text { /time }\end{array}$ & $\begin{array}{l}\text { Experimental } \\
\text { Result/time }\end{array}$ & Error $/ \%$ \\
\hline \multirow{3}{*}{ (1) } & \multirow{3}{*}{4.16} & 60 & 10722 & 11689 & 8.3 \\
\hline & & 56 & 11053 & 11867 & 6.9 \\
\hline & & 50 & 10656 & 11689 & 8.8 \\
\hline \multirow{3}{*}{ (2) } & \multirow{3}{*}{3.28} & 37 & 34810 & 39654 & 12.2 \\
\hline & & 30 & 34960 & 39088 & 11.3 \\
\hline & & 28 & 35560 & 40887 & 13.0 \\
\hline \multirow{3}{*}{ (3) } & \multirow{3}{*}{3.12} & -100 & 104326 & 114528 & 8.9 \\
\hline & & -110 & 114873 & 126347 & 9.1 \\
\hline & & -118 & 110287 & 124345 & 11.3 \\
\hline \multirow{3}{*}{ (4) } & \multirow{3}{*}{2.45} & -150 & 172708 & 187368 & 7.8 \\
\hline & & -160 & 175623 & 189074 & 7.1 \\
\hline & & -145 & 179236 & 188659 & 5.0 \\
\hline \multirow{3}{*}{ (5) } & \multirow{3}{*}{1.34} & -200 & 291486 & 329463 & 11.5 \\
\hline & & -220 & 292476 & 329793 & 11.3 \\
\hline & & -234 & 307563 & 328974 & 6.5 \\
\hline Average error & / & / & / & / & 9.27 \\
\hline
\end{tabular}

Table 7: Fatigue test results. 


\section{CONCLUSION}

hrough the finite element simulation and mathematical statistical multiple orthogonal regression experiments, the fatigue life prediction model of aluminum alloy thin plate self-piercing riveting structure is analyzed, and the functional relationships of fatigue life on roughness, residual stress and maximum stress are fitted. The main influencing factors are residual stress, the interaction between roughness and residual stress, and roughness.

The maximum stress is unchanged. In the range of lower roughness, the fatigue life increases as the residual stress decreases; when the residual stress is constant, the fatigue life decreases as the roughness increases.

Fatigue tests are performed on self-piercing riveting members with different roughness and residual stress. Compared with the simulation results, the average error is $9.27 \%$, indicating that the fatigue life simulation and analysis method of selfpiercing riveting of aluminum alloy sheet are reliable.

\section{ACKNOWLEDGMENTS}

he authors gratefully acknowledge the support from the National Natural Science Foundation of China (Grant No. 61941305), the Tianjin Science and Technology Project (Grant No.19YFFCYS00110), and the Natural Science Foundation of Tianjin of China (Grant No.18JCQNJC75000).

\section{REFERENCES}

[1] Li, Y., Li, Y., Lou, M., Lin, Z. (2012). Lightweighting of car body and its challenges to joining technologies, Jixie Gongcheng Xuebao/Journal Mech. Eng., 48(18), pp. 44-54. DOI: 10.3901/JME.2012.18.044.

[2] He, X., Wang, Y., Lu, Y., Zeng, K., Gu, F., Ball, A. (2015). Self-piercing riveting of similar and dissimilar titanium sheet materials, Int. J. Adv. Manuf. Technol. 80 (9-12), pp.2105-2115. DOI: 10.1007/s00170-015-7174-3.

[3] Zhang, C. yu., Gou, R. bin., Yu, M., Zhang, Y. jing., Qiao, Y. hu., Fang, S. ping. (2017). Mechanical and fatigue properties of self-piercing riveted joints in high-strength steel and aluminium alloy, J. Iron Steel Res. Int. 24(2), pp.214-221. DOI: 10.1016/S1006-706X(17)30030-4.

[4] Carandente, M., Dashwood, R.J., Masters, I.G., Han, L. (2016). Improvements in numerical simulation of the SPR process using a thermo-mechanical finite element analysis, J. Mater. Process. Technol. 236, pp. 148-161.

DOI: 10.1016/j.jmatprotec.2016.05.001.

[5] Chrysanthou, A. (2014).Fatigue behaviour of self-piercing riveted joints. Self-Piercing Riveting: Properties, Processes and Applications. DOI:10.1533/9780857098849.1.33.

[6] Jeong, C.H., Kim, D.Y., Oh, H.S., Cheon, S.S. (2018). FE analysis of Self-Piercing Rivet (SPR) process and tensile behaviours, J. Korean Soc. Precis. Eng. DOI: 10.7736/KSPE.2018.35.9.875.

[7] Liu, Y., Zhuang, W. (2019). Self-piercing riveted-bonded hybrid joining of carbon fibre reinforced polymers and aluminium alloy sheets, Thin-Walled Struct. 144, pp. 106340. DOI: 10.1016/j.tws.2019.106340.

[8] Zhang, X., He, X., Xing, B., Zhao, L., Lu, Y., Gu, F., Ball, A. (2016). Influence of heat treatment on fatigue performances for self-piercing riveting similar and dissimilar titanium, aluminium and copper alloys, Mater. Des. DOI: $10.1016 /$ j.matdes.2016.02.075.

[9] Zhao, L., He, X., Xing, B., Lu, Y., Gu, F., Ball, A. (2015). Influence of sheet thickness on fatigue behavior and fretting of self-piercing riveted joints in aluminum alloy 5052, Mater. Des. 87, pp.1010-1017.

DOI: $10.1016 /$ j.matdes.2015.08.121.

[10] Huang, L., Lasecki, J., Guo, H., Su, X. (2014).Fatigue and fretting of mixed metal self-piercing riveted joint. ASME International Mechanical Engineering Congress and Exposition, Proceedings (IMECE).

DOI: $10.1016 /$ j.ijfatigue.2015.10.018.

[11] Xing, B., He, X., Zeng, K., Wang, Y. (n.d.). Mechanical properties of self-piercing riveted joints in aluminum alloy 5052, Int. J. Adv. Manuf. Technol., 75(1-4), pp. 351-61. DOI: 10.1007/s00170-014-6152-5.

[12] Xing, B., He, X., Wang, Y., Yang, H., Deng, C. (2015). Study of mechanical properties for copper alloy H62 sheets joined by self-piercing riveting and clinching, J. Mater. Process. Technol. 216, pp. 28-36.

DOI: 10.1016/j.jmatprotec.2014.08.030. 
[13] Deng, C.J., He, X.C., Xing, B.Y., Wang, Y.Q., Zeng, K., Ding, Y.F. (2015). Mechanical properties of self-piercing riveted lap joints in dissimilar metal sheets of aluminum and copper, Jilin Daxue Xuebao (Gongxueban)/Journal Jilin Univ. (Engineering Technol. Ed., 45(02), pp.473-480. DOI: 10.13229/j.cnki.jdxbgxb201502021.

[14] Xing, B., He, X., Wang, Y., Liu, F. (2016). Fatigue properties and failure mechanisms of self-piercing riveted joints in aluminium alloy, Hanjie Xuebao/Transactions China Weld. Inst.37(06), pp.50-54+131.

[15] Sun, X., Stephens, E. V., Khaleel, M.A. (2007). Fatigue behaviors of self-piercing rivets joining similar and dissimilar sheet metals, Int. J. Fatigue,97, pp.20-28, DOI: 10.1016/j.ijfatigue.2006.02.054.

[16] Choi, D.H., Han, D.W., Kim, H.K. (2017). Fatigue life estimation of self-piercing riveted aluminum joints under mixed-mode loading, Int. J. Fatigue,97, pp.20-28. DOI: 10.1016/j.ijfatigue.2016.12.019.

[17] Franco, G. Di., Fratini, L., Pasta, A. (2012). Fatigue behaviour of self-piercing riveting of aluminium blanks and carbon fibre composite panels, Proc. Inst. Mech. Eng. Part L J. Mater. Des. Appl. 226(3), pp. 230-241. DOI: $10.1177 / 1464420712443753$.

[18] Ueda, M., Miyake, S., Hasegawa, H., Hirano, Y. (n.d.). Instantaneous mechanical fastening of quasi-isotropic CFRP laminates by a self-piercing rivet, Compos. Struct., 94(11),3388-3393. DOI: 10.1016/j.compstruct.2012.04.027.

[19] Gay, A., Lefebvre, F., Bergamo, S., Valiorgue, F., Chalandon, P., Michel, P., Bertrand, P. (2016). Fatigue performance of a self-piercing rivet joint between aluminum and glass fiber reinforced thermoplastic composite, Int. J. Fatigue 83, pp. 127-134. DOI: 10.1016/j.ijfatigue.2015.10.004.

[20] Huang, L., Shi, Y., Guo, H., Su, X. (2016). Fatigue behavior and life prediction of self-piercing riveted joint, Int. J. Fatigue 88, pp.96-110. DOI: 10.1016/j.ijfatigue.2016.03.015.

[21] Yang, z., Zhang, y., Jiang, c. (2016). Dynamic reliability analysis of mechanical parts under actual operation conditions.Journal of Northeastern University(natural science).40(11), pp.1584-1589. 